\title{
Changes in the male voice at puberty
}

\author{
M L L Harries, J M Walker, D M Williams, S Hawkins, I A Hughes
}

Voice Clinic, Royal Sussex County Hospital, Brighton M L L Harries

Department of Paediatrics, St Mary's Hospital, Portsmouth J M Walker

Department of Linguistics, University of Cambridge

S Hawkins

Department of Paediatrics, University of Cambridge D M Williams

I A Hughes

Correspondence to: Professor I A Hughes, Department of Paediatrics, Addenbrooke's Hospital, Box 116, Hills Road, Cambridge CB2 2QQ.

Accepted 15 July 1997
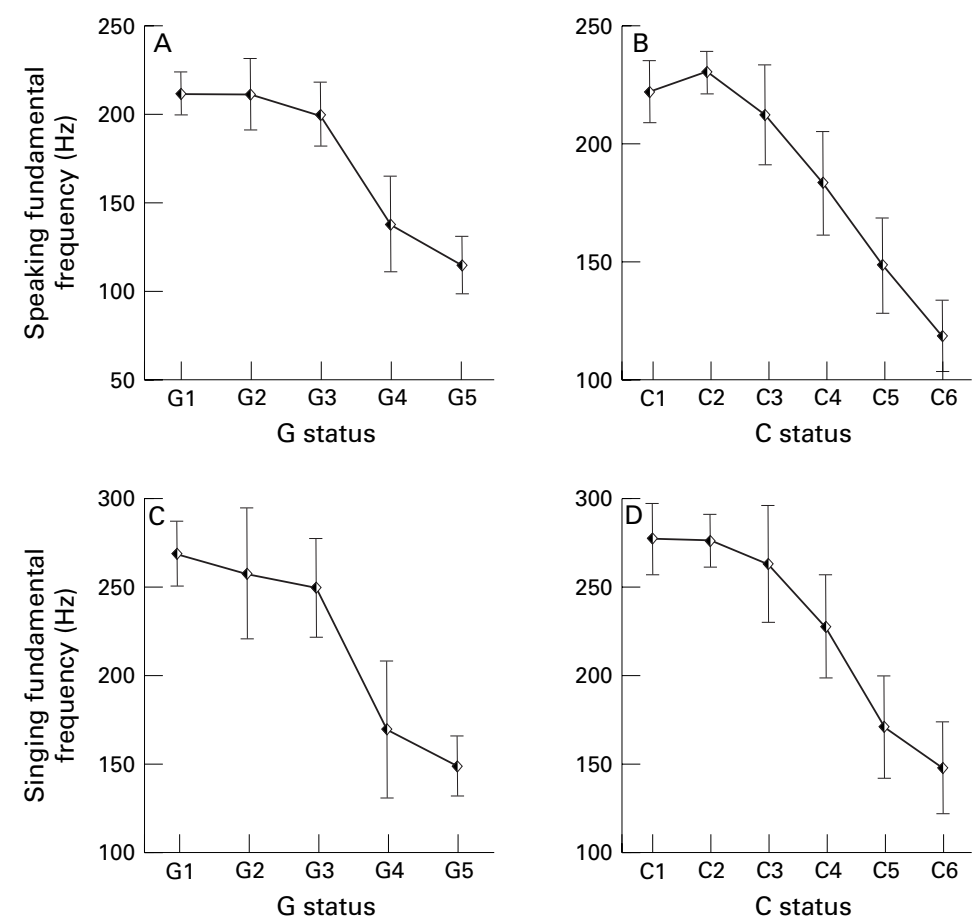

Figure 1 Relation between the stages of puberty and $(A, B)$ speaking fundamental frequency and $(C, D)$ singing fundamental frequency. $G$ and $C$ refer to Tanner and Cooksey staging, respectively.

Keywords: fundamental voice frequency; puberty; testosterone

The maturation of the human voice as a function of age is characterised by changes in pitch, loudness, and a variety of tone qualities. ${ }^{1}$ The

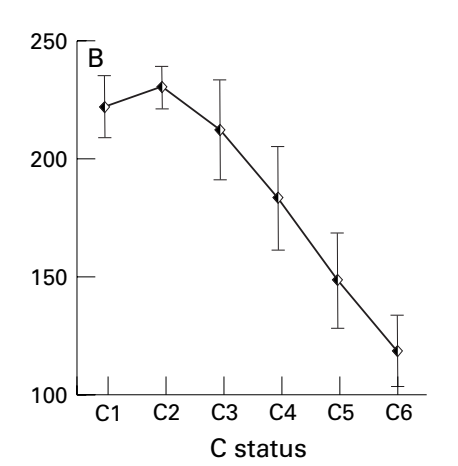

\begin{abstract}
The changes in the male voice in relation to the biological characteristics of puberty were assessed longitudinally in 26 boys. Speaking and singing fundamental frequencies were analysed in relation to the Tanner staging of puberty, saliva testosterone levels, and the Cooksey classification of voice analysis. There were abrupt changes in voice characteristics between Tanner stages G3 and G4 and more gradually from stages C3 to C5 of Cooksey. Although testosterone concentrations were not predictive of the changes, there was a correlation with testis volume. Voice fundamental frequencies were seen to change abruptly in late puberty, in contrast with previous studies. There is a good correlation between the Tanner and Cooksey methods of classification during male puberty.

(Arch Dis Child 1997;77:445-447)
\end{abstract}

SALIVARY TESTOSTERONE PROFILE

This was performed by collecting three separate $5 \mathrm{ml}$ samples of saliva at $2000 \mathrm{~h}$ the night before, $0800 \mathrm{~h}$ on the day of recording, and at the time of recording (between 1000 and 1600 h). Saliva testosterone concentrations were determined by immunoassay; the assay sensitivity was 9 pmol. $^{7}$ An average of the three readings was taken to minimise daily variation and the value was converted to a log correlate for analysis because of a non-Gaussian distribution.

ACOUSTIC AND MUSICAL RECORDINGS

Human tissue is a moderately good conductor of electricity and behaves like a resistor for which Ohm's law applies. This concept forms 

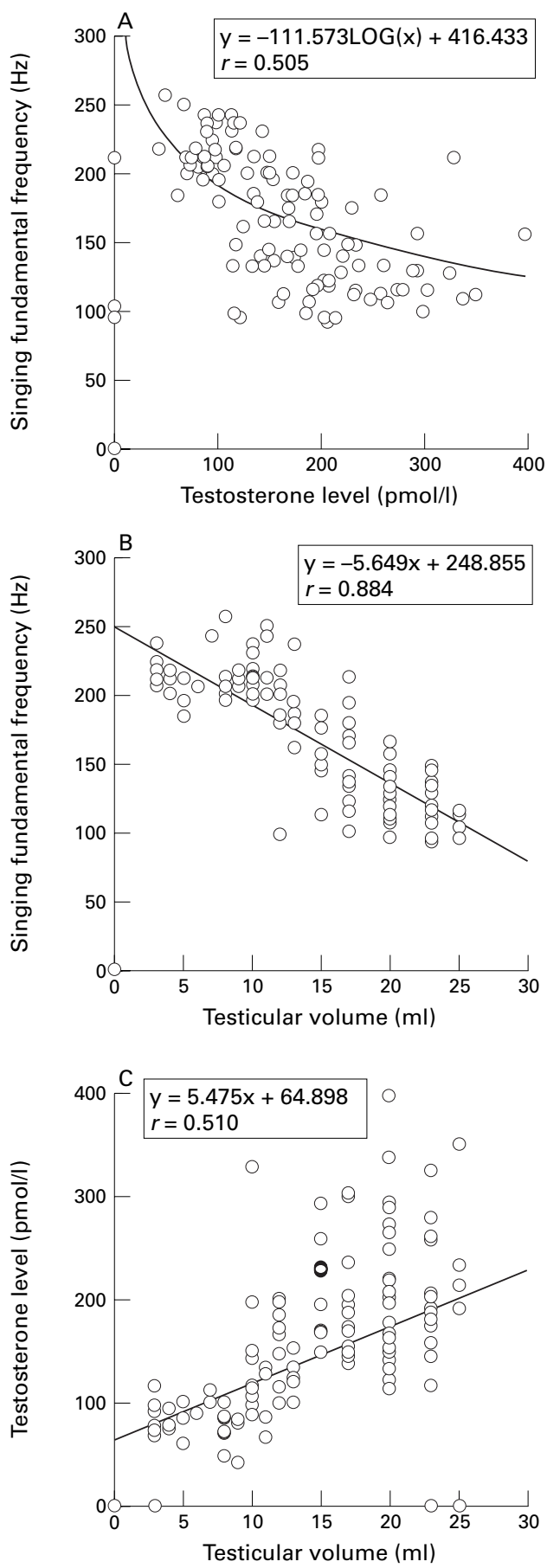

Figure 2 Relations between singing fundamental frequency and $(A)$ testosterone levels and $(B)$ testicular volume. (C) Relation between testosterone levels and testicular volume.

the basis of electrolaryngography. ${ }^{8}$ During cord abduction, air acts as an electrical resistor and current flow across the larynx is at a minimum. In cord adduction, the contact area allows a current to flow, thereby increasing the electrical signal across the larynx. The method is non-invasive and does not require sedation.

Acoustic recordings were performed in a sound treated audiology booth using a laryngograph (portable laryngograph processor) and the measurements were analysed on an IBM PC/AT computer with a PCLX system. The

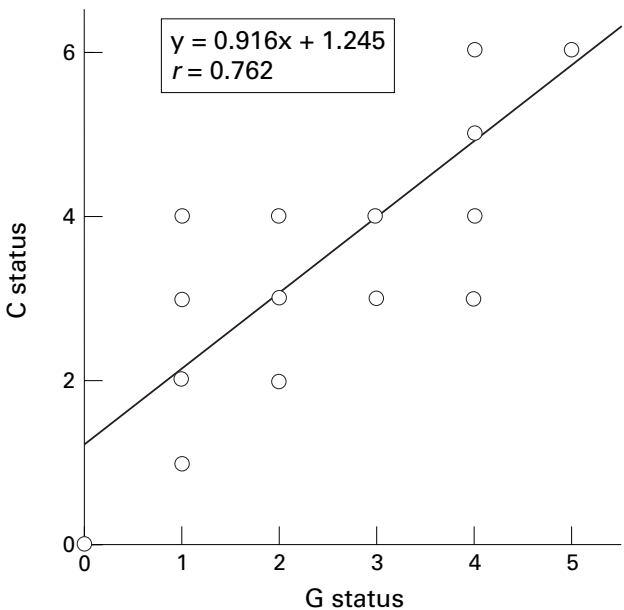

Figure 3 Relation between the Tanner and Cooksey classification systems of puberty.

laryngograph electrodes were strapped in position to give the best signal, which was continually monitored on an oscilloscope during the recording and recorded on uniaxial, chromic, high bias Sony recording tape.

None of the boys was a chorister. Each boy spoke his name and then read the phonetically recognised passages 'The rainbow passage' and 'Arthur the rat'. He was then asked to sing a comfortable note within his modal range and to ascend and descend the musical scale from this baseline without entering the falsetto or vocal fry registers. Lastly, each boy sang the tune to 'Happy birthday' at a comfortable pitch. Modal register was assessed using laryngography by comparing the recorded sung notes with those of a tuned piano keyboard. ${ }^{9}$ The following measurements were performed at each recording: the mean speaking fundamental frequency; the mean singing fundamental frequency of modal voice; and the speaking and singing ranges of the voice.

ATTENDANCE

The attendance rate was $94 \%$ throughout the study. Laryngoscopy was performed at each visit to confirm that the vocal folds were healthy.

\section{Results}

Weight and height generally increased between assessments at various stages, but the differences were not statistically significant other than for weight between stages $\mathrm{C} 4$ and $\mathrm{C} 5$ (data not shown). Figure 1 summarises the changes which occurred in the acoustic parameters studied. The speaking and singing fundamental frequencies showed a relatively large and significant change between Tanner stages G3 and G4, whereas there was a more gradual change during stages $\mathrm{C} 3, \mathrm{C} 4$, and $\mathrm{C} 5$ according to the Cooksey voice classification.

Figure 2 shows the relations between testosterone concentrations, testis volume, and singing fundamental frequency. The correlations were poor, except for a clear relation between testis volume and singing fundamental frequency. 
Figure 3 compares the $\mathrm{G}$ and $\mathrm{C}$ stages determined during each assessment. There was a more gradual index of progression through puberty according to the $\mathrm{C}$ staging, where the larger difference between stages G3 and G4 (see fig 1) is minimised by the use of six rather than five stages.

\section{Discussion}

Previous studies of the male voice have correlated voice changes with chronological age rather than with pubertal stage. ${ }^{10} 11$ The range in the age of onset and the tempo of pubertal development in these studies were extreme, whereas the present study compared boys at the same pubertal stage. The data indicate that the maximum vocal change occurs between stages G3 and G4 and not towards the beginning of puberty as implied in previous studies. ${ }^{12}{ }^{13}$ Nevertheless, the use of acoustic parameters and the Cooksey classification indicates that measurable changes are taking place earlier in puberty before the development of overt voice 'breaking'.

Anthropometric changes are considerable at the time of male puberty. Changes also occur in the organs of phonation. ${ }^{14}$ These include an increase in breathing capacity and an increase in neck length and width, which leads to a relative descent of the larynx, and subsequent enlargement of the vocal tract and resonatory system. Growth of the paranasal sinuses and nasal turbinates, with atrophy of the tonsils and the adenoids, also affects vocal quality. In natural speech, however, perceived male voice quality depends on how the vocal cords vibrate, including fundamental frequency, while gender specific vocal tract resonance is less important. ${ }^{15}$

There was no relation in this study between salivary testosterone concentrations and voice parameters, although for the entire group there was an increase in testosterone from stage 1 to the final stage using both the G and C classifications. There was a correlation between testis volume and voice parameters, which was surprising as testis size is dependent more on seminiferous tubular development than on Leydig cell mass. Nevertheless, testosterone levels, especially when measured in the early morning, increase significantly with a testis volume of at least $8-10 \mathrm{ml} .^{16}$ Our findings coincide with previous studies showing this relation with voice parameters. ${ }^{17}$

Other studies of the changes in the male voice at puberty have used chronological age or the Tanner $G$ staging of puberty to monitor trends. This study shows a good correlation between the $\mathrm{G}$ and $\mathrm{C}$ methods of staging and

\section{Key messages}

- Voice 'breaking' is a late event in male puberty

- Changes in voice fundamental frequencies correlate with testis volume, but not testosterone levels

- There is a clear relation between the Tanner stages and a Cooksey musical classification during male puberty

confirms the Cooksey system as valid for monitoring an individual subject longitudinally through puberty.

We thank the Tenovus Cancer Research Centre, Cardiff for measuring salivary testosterone concentrations. Margaret Griffiths, Jane Beckinsale, Andrew Slater, and Thomas Baer provided assistance for this study.

1 Hollien $\mathrm{H}$, Jackson B. Normative data of the speaking fundamental frequency characteristics of young adult males. Fournal of Phonetics 1973;1:117-20.

2 Pederson MF, Moller S, Krabbe S, et al. A multivariate statistical analysis of voice phenomena related to puberty in choir boys. Folia Phoniatica 1985;37:271-8.

3 Vuorenkoski V, Lenko HL, Tjerlund P, et al. Fundamental voice frequency during normal and abnormal growth, and after androgen treatment. Arch Dis Child 1978;53:201-9.

4 Tanner JM. Growth at adolescence. Oxford: Blackwell Scientific, 1962 .

5 Cooksey JM, Becket RL, Wiseman R. A longitudinal investigation of selected vocal, physiologic and acoustic factors associated with voice maturation in the junior high school male adolescent. Proceedings of a research symposium on the male adolescent voice. Vol 1. Buffalo: State University of New York, Buffalo Press, 1984: 4-60.

6 Barresi AL, Bless D. The relation of selected aerodynamic variables to the perception of tessitura pitches in the adolescent changing voice. Proceedings of a research symposium on the male adolescent changing voice. Vol 1. 97-110. State University of New York, Buffalo Press, 1984:

7 Butler GE, Walker RF, Walker RV, et al. Salivary testosterone levels and the progress of puberty in the normal boy. Clin Endocrinol 1989;30:587-96.

8 Fourcin AJ. Electrolaryngographic assessment of phonatory function. Fournal of Phonetics 1987;14:435-42.

9 Cooksey JM. Do adolescent voices 'break' or do they transform? Voice 1993;2:15-39.

10 Hollien H, Malik E. Evaluation of cross-sectional studies of adolescent voice changes in males. Speech Monographs 1967;34:80-4.

11 Tosi O, Postan D, Bianculli C. Longitudinal study of children's voices at puberty. XVth International Congress Logoped Phoniatr. Basle: Karger, 1976: 486-90.

12 Billewicz WZ, Fellowes M, Thomson AM. Pubertal changes in boys and girls in Newcastle-upon-Tyne. Ann Hum Biol 1981;8:211-9.

13 Karlberg P, Taranger J. The somatic development of children in a Swedish urban community. Acta Paediatr children in a Swedish urb

Scand Suppl 1976;256:1-148.
Weiss DA. The pubertal change of the human voice. Folia Phoniatrica 1950;2:126-59.

15 Klatt DH, Klatt LC. Analysis, synthesis and perception of voice quality variations among female and male talkers. f Acoust Soc Am 1990;87:820-57

16 Wu FCW, Brown DC, Butler GE, et al. Early morning plasma testosterone is an accurate predictor of imminent pubertal development in prepubertal boys. $\mathcal{F}$ Clin Endocrinol Metab 1993;76:26-31.

17 Pederson MF, Moller S, Krabbe S, Bennett P. Fundamental voice frequency measured by electroglottography during continuous speech. A new exact secondary sex characteristic in boys in puberty. Int $\mathcal{f}$ Pediatr Otorhinolaryngol 1986;11:21-7. 